\section{THE STORAGE OF RADIUM IN WAR TIME}

\author{
BY
}

\section{PROFESSOR F. L. HOPWOOD, D.Sc.}

\author{
St. Bartholomew's Hospital
}

On the outbreak of the present war practically the whole of the supplies of radium in London were concentrated at four centres and were placed for security in suitable containers at the bottom of specially prepared bore-holes fifty feet deep. This method of storage was designed in the first instance simply as a temporary measure, until the different bodies and institutions responsible for radium treatment could elaborate plans for war-time radium service. In most cases it was not contemplated that frequent or daily raising and lowering of the radium in the bore-hole would be required as part of a war-time radium service. During the present phase of the war, however, the question of carrying on radium treatment in London has become an urgent one, and demands a reconsideration of the suitability of the bore-holes for radium storage where regular treatment of patients has been resumed or is contemplated.

The following description of the arrangements made at St. Bartholomew's Hospital for storing radium needles, etc., so that the radium service could be maintained when desired may be of interest to others who are faced with similar conditions. Special attention has been given here $(a)$ to the protection of the personnel, and $(b)$ to the ease of access to the radium supplies, as well as to safeguarding the radium from the effects of high explosives or accidental loss. To secure these aims a special radium "bucket" has been designed, which is loaded and unloaded in a separate protected loading-hole situated by the side of the main bore-hole. The transference of the bucket from the one hole to the other is effected in a few seconds by a swivel jib and windlass.

\section{The Radium Bucket}

The radium bucket takes the form of two co-axial brass cylinders provided with rigid handles, the inner one of which

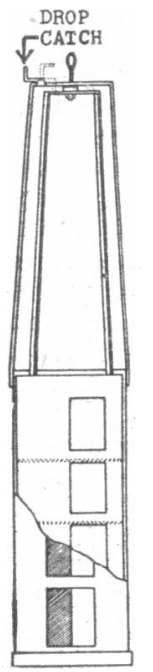

Fig. 1.-The radium bucket.

can be rotated with respect to the outer cylinder (Fig. 1). The inner cylinder is divided into four compartments, each provided with an opening big enough to permit the introduction of the largest radium package it is desired to store. Corresponding openings are cut in the outer cylinder, and the operation of opening or closing the inner container consists merely in rotating it through 180 degrees, the correct relative disposition of the holes being ensured by a drop-catch which locks the handle-bars together. The use of swinging doors and of a separate lock and key to each compartment has been eliminated, and it is possible for the operator to open or shut the container in the hole without bringing his hands nearer than two feet from the radium.

\section{The Loading-hole}

The loading-hole is of the same diameter (eleven inches) as the main bore-hole, but extends only from the ground level up to a height of four feet. Together with the main borehole it is encased in a mass of masonry, the wall on the operator's side being made of barium concrete six inches thick. The radium is loaded and unloaded through a hole in this wall about two feet above the floor, the openings in the bucket being maintained in correct register by drop-catches situated at the top of the hole which engage the handle-bars. Suitable marks on the handle-bars enable the operator to adjust the level of any compartment with respect to the hole by a slight turn of the hand winch. The introduction and withdrawal of radium from the bucket only while it is in the loading hole removes all possible risk of dropping radium containers to the bottom of the fifty-foot bore-hole.

\section{Protected Table}

A protected table, enclosed on two sides by the concrete wall and block of masonry respectively, serves as a convenient place of temporary storage of radium containers while the bucket is being lowered to or raised from the depth of the bore-hole. A perspective drawing of the building covering the bore-hole is shown in Fig. 2. The dimensions of the building are $7 \mathrm{ft} .6 \mathrm{in} . \times 9 \mathrm{ft} . \times 10 \mathrm{ft}$. high, its unusual height being necessary to provide clearance for the jib when swinging the four feet tall bucket from one hole to the other. It is

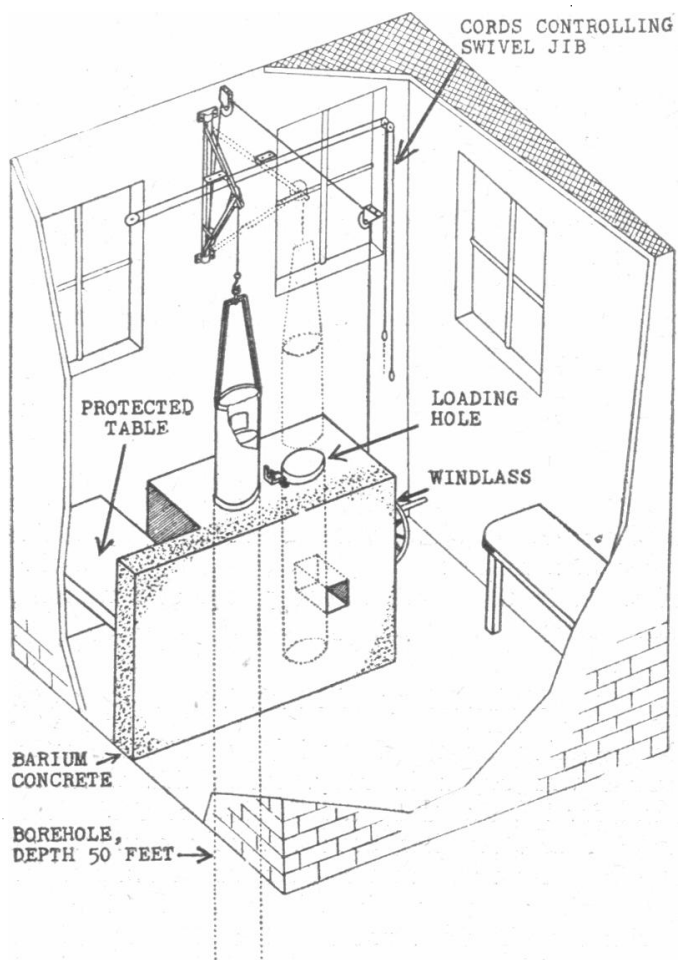

Fig. 2.-Apparatus used for raising and lowering the bucket containing radium.

situated in an area outside the main hospital buildings, but in convenient proximity to the room of the radium custodian.

Thanks are due to Mr. P. W. Hubbard, F.R.I.B.A., architect, and to Mr. Nye, clerk of the works, to the hospital, for their co-operation in planning this scheme and carrying it into effect. The cost of the bore-hole has been defrayed by the King Edward Hospital Fund for London. 